\title{
Corporate social responsibility (CSR) - A Key Factor to an Organization's Success
}

\author{
Tang Kun-Hsiang \\ Feng Chia University, Taichung, Taiwan \\ E-mail address tenwha@gmail.com
}

\begin{abstract}
Corporate social responsibility (CSR) is not a refreshing concept for the management of an organization in recent years. This concept refers to a firm, which has more responsibilities to adapt the needs of objectives apart from its stakeholders and owners in commercial, legal, ethical, and environmental ways (Beal and Goyen, 2005), and the responsibilities are achieved by meeting or exceeding the commercial, ethical, legal and philanthropic expectation from these objectives. The concept of corporate social responsibility was firstly introduced by the publication of Bowen's Social Responsibility of Businessmen in 1953, while almost all known companies have integrated this spirit into their business model. Nowadays, the promotion of corporate social responsibility has even become not only the wider responsibilities in which an organization contributes to society but also an approach to promote an organization's corporate image (Chang, 2009). The purpose of this paper is to briefly discuss the concept of corporate social responsibility regarding economic, ethical, legal, and philanthropic aspects, and the objectives served by corporate social responsibility such as environments, the society, and the public. This paper then explains how the realization of CSR from one organization can bring effects to its stakeholders and how the organization can obtain benefits from the implementation. Finally, this paper includes two cases from well-known companies in Taiwan, namely TSMC (Taiwan semiconductor manufacturing company) and FPG (Formosa Plastics Group) about how these companies successfully realize corporate social responsibility, and the impacts that influence the stakeholders, and the benefits they obtain for their corporate images.
\end{abstract}

Keywords: CSR

\section{INTRODUCTION}

This is an open access article under the $\mathrm{CC}-\mathrm{BY}-\mathrm{NC}$ license.

Corporate social responsibility (CSR) is a type of business model that a firm aims to be socially accountable to its surrounding objectives, such as its stakeholders, the society, and the environment, beyond the consideration of making a profit. Rather than corporate image, corporate social responsibility is more about the realization of corporate ethical value (Hasan, Kobeissi, Liu and Wang, 2018). In order to realize corporate social responsibility, there are four primary aspects, which are ethics, environment, philanthropy, and commercial (Beal and Goyen, 2005). Regarding the ethical aspect, a firm should ensure good welfare and labor practices to its employees and the employees from the partnership.. 


\section{LITERATURE REVIEW}

Ensuring good labor practices includes providing the employees a safe and healthy workspace environment that each employee should hold reasonable pay and fair workload without the concern of any type of discrimination such as gender and religion. Apart from ethics, legal responsibility is that a company must obey the laws and rules which meets the expectation of the public as well as the other business. These regulations are maintained by agencies from governmental organizations in order to maintain fair trades. For example, it is the responsibility of companies to pay taxes to the governments and maintain a clear record for such transactions under these regulations. Environmental responsibility is that a company must respect the environment and maintain a good environment for other objectives in society. With regard to environmental responsibility, it is the responsibility to lead the business to sustainability. Firstly, a company must consider the approaches to minimize the negative impacts on the environment from its business under a set of regulations. For instance, a company is responsible for sewage disposal to ensure that the negative impacts on the rivers are minimized before the sewage is exhausted. Secondly, a company shall consider how to introduce positive impacts to the environment and the society beyond the consideration of gaining profit. For example, many organizations have cooperated with local communities to build wood in order to reduce the amount of greenhouses gases from the environment and adopted electricity from solar power. How a company contributes to society is the responsibility of philanthropy. Apart from the other responsibilities, the responsibility of philanthropy is not mandatory while it is beneficial for corporate images. The most common way to achieve the responsibility is to donate to disadvantaged groups and invite employees for their volunteers to participate in philanthropic activities such as beach clean-up. These activities normally do not lead to any profit to an organization but help the firm to gain a better corporate image from the public expectation. Finally, the responsibility of commercial is how a company strike a balance among legal, ethical, environmental, and philanthropic practice. It is the responsibility that a company finds a solution that can not only facilitate business growth but can also make profits that benefit society and the communities.

Nowadays, more and more organizations have started to consider the importance of corporate social responsibilities and adopted this model into their business in order to promote their corporate social image (Chang, 2009). There are four advantages that organizations can acquire from the realization of corporate social responsibility. Firstly, the good realization of corporate social responsibility can lead to great employee satisfaction. This is because the employees who participate in the activities can build more connections with other objectives such as local communities and other stakeholders. The employees then gain motivation and respect from these activities, which leads to greater self-satisfaction. Secondly, the realization of corporate social responsibility can result in a greater public image for the corporate. This is because the communities are benefitted from the company that achieves their responsibilities, and they then start to trust the company that is helping their communities. This can then increase the company's reputation. Thirdly, when the company's reputation increases and the company becomes more trustworthy, the customers are then likely to be more loyal. Finally, the realization of corporate social responsibility can also help the employees to gain more creativity from participating in new things and being connected with more communities.

\section{RESEARCH METHODOLOGY}

This section includes the research method, which analyzes two cases from two well-known companies in Taiwan about the approach they achieve corporate social responsibility, how they bring benefits to the society, the local communities, and their partners and reduce the negative impacts on the environment. 
Formosa Plastic Group (FPG) is one of the well-known plastic companies in Taiwan founded in 1954. FPG originally started the business from plastic manufacturing while they have expanded its business into several domains, such as biotechnology, petrochemical, and electronics components (FPG, 2019). Although FPG has successfully established a good corporate image to the public, they have also caused several controversies since their establishment. These controversies are primary because the types of products FPG manufactures often lead to pollution in the environments, which affects the local communities. This has led to several debates on whether the business model that FPG adopts is appropriate to society or not. However, FPG has taken these controversies into serious consideration and planned several actions to realize their corporate social responsibility to minimize the negative impacts on their business from the controversies. FPG has started to publish the report of their corporate social responsibility, which clearly records their actions and plans to realize their corporate social responsibility from the perspective of the economy (13 plans), environments (11 plans), and society (14 plans) since 2008. For instance, the CSR report in 2019 claimed that FPG planned to promote the development of artificial intelligence and apply the outcome of the promotion into their business model in order to increase their profits by 160 million TWD as well as creating more job opportunities for the public from the perspective of economy. Regarding the perspective of environments, the report claimed that FPG planned to adapt the recycling economy into its business model in order to recycle the waste from the manufacturing for reuse, which can reduce the negative impacts on the environment. With regard to the perspective of society, FPG has contributed 700 million TWD into philanthropic activities in local communities such as schools and disadvantaged groups. Although there were several environmental controversies caused by FPG, the local communities tend to accept the benefits that were brought from FPG and accept the great efforts which they have contributed. This not only helps FPG to be a trustworthy partner for the local communities but also promotes their corporate image to the public.

Taiwan semiconductor manufacturing company (TSMC) is one of Taiwan's largest companies and the most valuable companies in the world, founded in 1987 (TSMC, 2019). The advanced technologies in semiconductor foundry that TSMC develops have attracted many leading fabless companies such as Apple Inc., Advanced Micro Devices (AMD) and Nvidia to be their customers, which has led to great success for TSMC. Apart from its advanced technologies provided to its customers, the achievement of corporate social responsibility for TSMC is also one of the key factors resulting in their success. According to TSMC's corporate social responsibility report in 2019, they have invested more than 2.9 billion TWD into the development of new advanced technologies which continuously create more and more job opportunities for the local communities, and the company value has increased to 8.6 trillion until 2019, which contributes a significant amount of tax to the government from the perspective of the economy (TSMC, 2019). Regarding environmental responsibility, TSMC has invested more than 0.9 billion TWD in green energy in order to reduce the negative impacts on nature, and the reusability of the waste from its manufacturing has achieved $96 \%$, which also leads to less than $1 \%$ for waste burial in the last ten years (TSMC, 2019). With regard to social responsibility, TSMC has contributed 584 million TWD into philanthropic activities that benefit more than 221 thousand people in society (TSMC, 2019). The amount of time that their volunteers contribute to these philanthropic activities has achieved more than 83 thousand hours in 2019 (TSMC, 2019). This also helps TMSC to win the title of one of the most admired companies in the world, according to Fortune magazine in 2019. Because of the great efforts which TSMC contributes to society and their corporate image to the public, TSMC has become one of the top choices for graduates every year. 


\section{FINDING AND DISCUSSION}

According to the case studies from prevision section, it is found that the waste produced by manufacturers is often considered to harm the environments such as a river, the air, the land, and the severity of the impacts that may vary depending on the types of manufacture. These impacts are very likely to cause controversy among the local communities and society. It is the challenge that every manufacturing companies must face and deal with. For the companies which poorly realize their corporate social responsibility, it often leads to debates about whether the types of manufacturing should exist or not in the society as the negative impacts on the society are too significant while the benefits that the communities can obtain are slight. This can result in great harm to the corporate image when they become untrustworthy due to the controversy. However, fully achieving corporate social responsibility may help these organizations to reduce the impacts of these controversies by benefiting the communities. For instance, the local communities understand that the form of manufacturing from FPG's business model may introduce pollution to their local nature, while they tend to accept that FPG provides great offers such as scholarships to the local schools, a donation to disadvantaged groups, and healthcare benefits to the local communities at the same time to reduce the pollution by recycling their waste. Although this does not change the fact that the environment and nature are polluted, the full realization of corporate social responsibility can lead to a trade-off between the company and the communities. It may reduce the severity of these controversies when local communities feel that they are benefited from the companies and start to trust the company, which can also prevent more damages to the corporate image. On the other hand, it is also found that the achievement of corporate social responsibility can help one organization to promote its corporate image, which can increase the admiration for a company. For example, in recent years, TSMC has tried to integrate its business with sustainability by promoting green power and investing a massive amount of money into the facilities for recycling energy as well as waste. Furthermore, TSMC considers its employees as the most important asset and provides excellent benefits to the employees. As a result, TSMC is always listed as one of the companies which the public wants to join in the last decades. Apart from its famous advanced technologies in semiconductor manufacturing, the philanthropic activities that TSMC has hosted also help TSMC to establish a great corporate image in society.

\section{CONCLUSION AND FURTHER RESEARCH}

To sum up, rather than the responsibilities that a company should take for society, achieving corporate social responsibility can also be considered as an approach to promote business. Although this is likely to lead to additional costs for a company, it can lead to a win-win situation between the company and the communities.

\section{REFERENCES}

Bowen, H. R. (1953). Social responsibilities of the businessman. New York: Harper.

Beal, D., \& Goyen, M. (2005). Introducing corporate finance. John Wiley \& Sons Australia, Ltd. Chang, C. (2009). The relationships among corporate social responsibility, corporate image, and economic performance of high-tech industries in Taiwan. Qual Quant 43, 417

Hasan, I., Kobeissi, N., Liu, L., \& Wang, H. (2018). Corporate social responsibility and firm financial performance: The mediating role of productivity. Journal of Business Ethics, 149(3), 671-688.

Taiwan Semiconductors Manufacturing Company (2019).Corporate Social Responsibility Report 2019. Available at: https:/csr.tsmc.com/download/csr/2019-csr-report/english/pdf/e-all.pdf 
Proceeding on Japan International Business and Management Research Conference (JIBM), Vol. 1 (1), 49-53

Corporate social responsibility (CSR) - A Key Factor to an Organization's Success

Tang Kun-Hsiang

Formosa Plastic Group (2019). Corporate Social Responsibility Report 2019. Available at: https://www.fpg.com.tw/tw/csr/report 